\title{
THE IMPACTS OF SITE SELECTION AND PLANNING OF A HISTORIC SETTLEMENT ON A SUSTAINABLE RESIDENCE
}

\author{
CHU,Y.-C. ${ }^{1}-$ HSU, M.-F. ${ }^{1}-$ HSIEH, C.-M. ${ }^{2 *}$ \\ ${ }^{I}$ Department of Architecture, Nation Cheng-Kung University, \\ 1 University Road, Tainan, Taiwan R.O.C. \\ (tel: $+88-69-8827-1644)$ \\ ${ }^{2}$ Department of Urban Planning, BIG Data and Urban Analytics LAB, \\ Tongji University, 1239 Siping Rd., Shnaghai, China \\ *Corresponding author \\ e-mail: chunming@tongji.edu.cn; tel:+86-21-6598-3148; fax: +86-21-6598-1002 \\ (Received $12^{\text {th }}$ Aug 2016; accepted $15^{\text {th }}$ Nov 2016)
}

\begin{abstract}
To find a sustainable living environment, ancestors looked to the site selection method of traditional Feng Shui from ancient China, evaluating and selecting the place most suitable to live in. The current location, environmental conditions, and building clusters of the Hua Zhai Settlement meet the most fundamental criteria of site selection. Further analysis of the local weather data from the last thirty years highlighted the most significant weather factor impacting Hua Zhai Settlement: wind. This factor is used in Computational Fluid Dynamics (CFD) wind environmental simulation, the results of which show that settlements that adhere to the most basic site selection principles are able to provide residents with a more comfortable living environment, allowing people to live sustainably. This proves that Feng Shui is indeed the accumulation of rules governing our living experiences.
\end{abstract}

Keywords: traditional settlement; CFD; Feng Shui; wind environment; sustainable planning

\section{Introduction}

To look for a sustainable residence environment, people from the past relied on their knowledge and experiences in traditional Chinese geomancy to screen, evaluate, and select a suitable location to live in. (He, 1995) Site selection includes analysis of the terrain, location, and direction to ensure the residents' quality of residence and level of comfort, which, in turn, affect health, good fortune, etc. The location of the Hua-Zhai settlement is closely related to Chinese geomancy knowledge, which was initially used by the residents for site selection. They believed that the place is suitable for settlement and this belief has proven true through the centuries.

The location of the historical settlement is closely associated with the knowledge of Feng Shui, which is part of Chinese tradition (Yi et al., 1996; Makand Ng, 2005).At initial stage of the development of historic settlement, usually there was a group of residents with blood relationship who consulted Feng Shui Masters to find a proper environment for sustainable residence in order to construct a huge amount of orderly arranged buildings with guaranteed residence quality.

With the climate change and the development of the times, the surrounding environment of Hua-Zhai settlement has already changed. A few of the low buildings in the settlement were removed and changed into buildings made of reinforced concrete and at a height of 2 to 3 stories. In order to analyze the impacts of initial site selection criteria of historic settlement and the planning of building groups on the sustainable residence, the oldest cadastral data and maps currently preserved will be 
used based on current status of Hua-Zhai settlement to restore the building groups and surrounding environment in early days of Hua-Zhai settlement while analyzing the oldest weather data. The analysis of 30 years of meteorological data has revealed that "wind" is the main climatic characteristic. Therefore, the CFD wind environment simulation has been implemented to analyze the relationship between wind and the site selection and planning of Hua-Zhai settlement.

Wind environment is one of the main factors affecting human comfort for pedestrians (Cheng and Wang, 2005; Hsieh et al., 2014).The wind field affecting the comfort of pedestrian is called pedestrian wind field, which generally refers the wind field 1.5 to $2 \mathrm{~m}$ above ground surrounding any building. Building configuration (e.g. height, width, arrangement and density) has been shown to have significant influence on wind at ground level.Wind speed affects pedestrian wind comfort and wind safety. Many countries have established standards for the speed of pedestrian wind fields in the light of the modern buildings (Mochida and Lun, 2008). The assessment standards of these countries are mostly based on Beaufort scale with some modification before being developed as regulations. The regulations are mainly for the maximum wind speed in the wind environment for protection against wind hazards. The other part is setting the evaluation criteria for assessing wind comfort as well as coming up with the minimum tolerable range of wind speed values. Disregarding gender and activity types, studies in Taiwan on the comfort level of pedestrian wind field consider $6-7 \mathrm{~m} / \mathrm{s}$ as the maximum wind speed range in terms of pedestrian wind field comfort (Guo, 2011). The gust speed $8 \mathrm{~m} / \mathrm{s}$ is the upper limit of pleasant wind speed among residential areas and wind hazard sensitive areas in Taiwan (Ding and Chu, 1999). According to the classification of Beaufort scale, an area with a wind speed less than $0.3 \mathrm{~m} / \mathrm{s}$ is in windless state, so the wind speed of a comfortable pedestrian wind field should at least be $0.3 \mathrm{~m} / \mathrm{s}$.

In addition, wind speed will affect the thermal comfort of human body (Hsieh et al., 2016). Proper natural ventilation will help human body exclude heat thus contributing to health and physical and mental comfort. In order to improve the quality of urban living and health environment of residents, Hong Kong government has been putting a great deal of emphasis on the natural ventilation of outdoor environment in recent years, and it has commissioned The Chinese University of Hong Kong to carry out a research on stipulation of air flow regulation. Relevant research results have revealed that, in a typical summer day, when air temperature is 27.9 and relative humidity is about $80 \%$, wind speed of 0.6 to $1.3 \mathrm{~m} / \mathrm{s}$ is required to achieve neutral thermal sensation (Yuan and $\mathrm{Ng}, 2011$ ).

In this study, CFD has been used as the analytical tool. CFD has been increasingly used to assess pedestrian-level wind conditions in urban areas (Blocken and Persoon, 2009; Blocken et al., 2012; Hsieh and Huang, 2016). The discussion focus of most essays on modern cities is on the microclimate (see Nugroho et al. 2007; Li, et al., 2012; D'Agostino et al., 2013). However, in contrast, there are much fewer researches on historical settlements' microclimate. Tang et al. (2012; 2014) provided simulations of the wind environment and the thermal environment with the general terrains of the historical settlement. The above-mentioned literature has not carried out detailed CFD simulation of the terrain and building groups. It has also not also used CFD in comprehensive discussions about the relationship between environmental conditions, historical settlement selection, and planning of the building groups. Therefore, in this study the 3D model of topographic environment and building groups of Hua-Zhai 
settlement in early days has been composed, and the impacts of topographic environment conditions of site selection and building groups planning of HuaZhaisettlement on sustainable residence has been investigated based the CFD analysis of wind field in the settlement.

\section{Materials and methods}

\section{Study area}

Hua-Zhai settlement is located on Wangan Island of Penghu County, Taiwan. The residents of Hua-Zhai settlement have kinship because a lot of people moved here together during the Ming dynasty. This settlement has been constructed for about 300 years till now and it covers a total area of $5900 \mathrm{~m}^{2}$. There are 160 buildings in total and among them, 52 historical buildings are well preserved. In 2004, World Monuments Watch announced that Hua-Zhai settlement was on the List of 100 most endangered sites.

The Taiwan Strait fronts Hua-Zhai settlement, with the five hills surrounding it on the other sides. (Fig. 2) These hills are respectively Hutou Mountain (Spot A), Tiantai Mountain (Spot B), Fengmen Mountain (Spot C), Hongmuqian Hill (Spot D) and Jianshanzai (Spot E). The average height of the five hills is the elevation of $29 \mathrm{~m}$. Because the natural landscape is like a flower, it is called as "Hua-Zhai". Hua in Chinese means flower. There is a small raised hill in the center of the settlement. Its shape is like a bud and so is called "Hua-Si."(Spot F). The residents consider the Hua-Si as a sacred land such that there should not be any farming or housing at this location, which is also called the Hsueh. It means central site in traditional Chinese Feng Shui theory.

In Feng Shui theory, a good spot must be a place for "Chi" to be accumulated, and also an intersection for Yin and Yang. In terms of the features of topographic environment, a fine place must be in front of hills (indicating Yin) and behind a body of water (indicating Yang) as a space surrounding by layers of mountains and waters. This space is called "Ming Tang", and the center of "Ming Tang" is "Hsueh", which is the best Feng Shui spot filled with the most "Chi" (Fig. 1). The topographic map of HuaZhai settlement is similar to the Feng Shui map, where layers of hills surround the HuaZhai settlement, and the Hua-Si is an elevated center of the spot surrounded by hills, which is also the Hsueh of Hua-Zhai settlement.

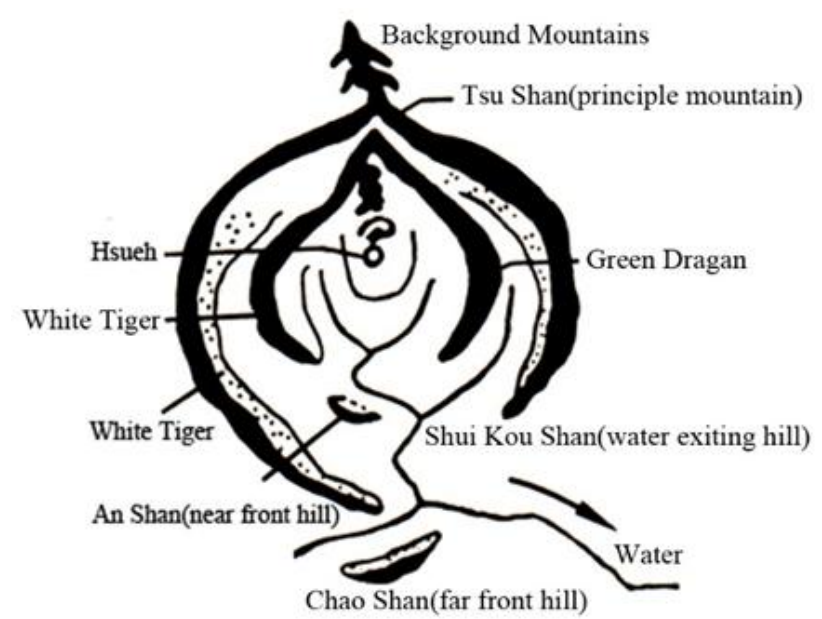

Figure 1. A fine place as defined by Feng Shui 


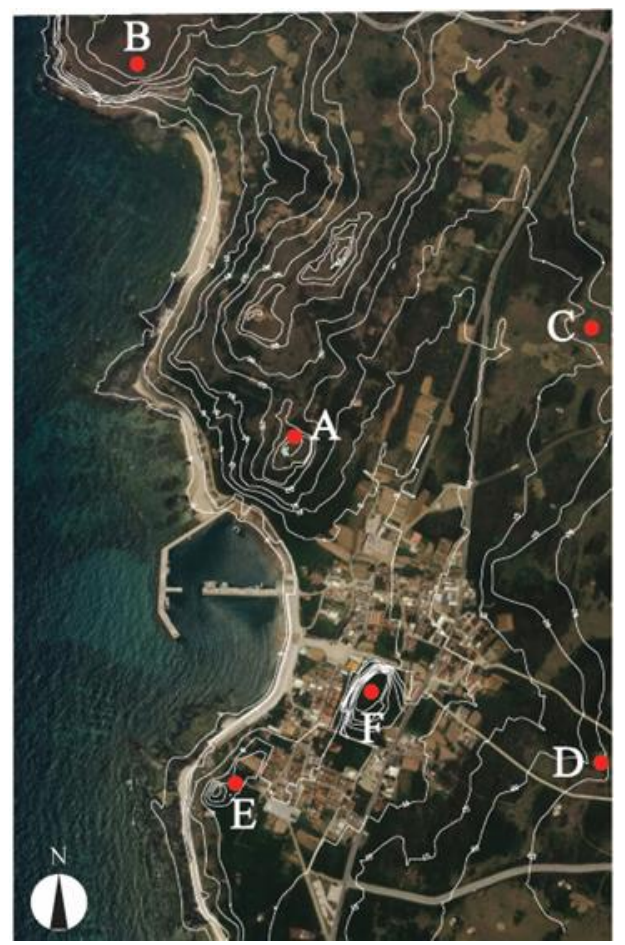

Figure 2. 2008 topographic map of Hua-Zhai settlement overlaid onto the orthophoto map

Penghu Weather Station is located on Wangan Island and was built in 1896. Due to the lack of detailed records of meteorological observation as well as meteorological data in 1896-1960, it in 1961 Penghu Weather Station had its earliest and most complete meteorological data. As a result, the thirty-year meteorological data from 1961 to 1991 was analyzed in this study.

Penghu Islands belong to subtropical monsoon climate and their average annual rainfall is around $1000 \mathrm{~mm}$. The seasons of the rainfall are unevenly distributed. An analysis of the thirty-year long average temperature shows that winter is from November to March, and the average temperature at $18.3^{\circ} \mathrm{C}$; summer is from June to September and the average temperature is $27.8^{\circ} \mathrm{C}$. The strong winter monsoon wind is its primary weather feature. There are strong winds around one third of the year. In winter, the average wind speed reaches around $7.15 \mathrm{~m} / \mathrm{s}$. The main wind direction is $\mathrm{NNE}$ and the maximum wind speed reaches $24.6 \mathrm{~m} / \mathrm{s}$. In summer, the average wind speed is $3.64 \mathrm{~m} / \mathrm{s}$ and the primary wind direction is SSW (Fig. 3). There is a great gap between the average wind speed in winter and summer. Monsoons not only impact the growth of crops and forest, but also cause a higher salinity of the soil, which becomes unsuitable for the growth of plants. As a result, there are only low grassland and shrubs on Penghu Islands. Wangan Island, the location of Hua-Zhai settlement, is surrounded by the sea. The terrain of the island is flat and there is no mountain to protect it, which leads to the suffering of the island from the wind damage throughout the year. Due to the impact of years of suffering from wind damage, the grassland, therefore, has become the most common landscape in the Hua-Zhai settlement. 


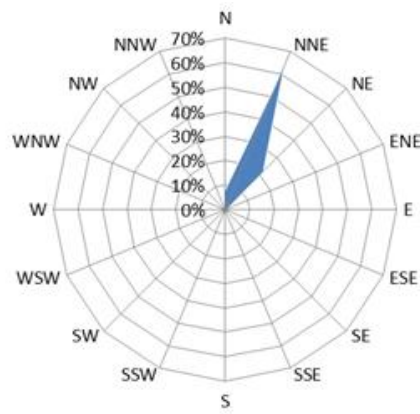

Winter

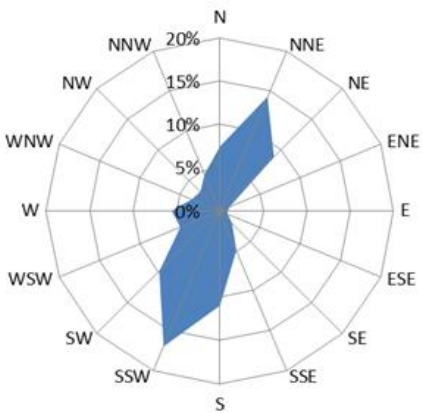

Summer

Figure 3. Wind rose diagram in Penghu weather stations from 1961-1991

\section{Methods}

\section{Reconstruction and $3 D$ modeling}

In order to understand the original conditions for the selection of the settlement, the study uses historical data and information on current status to recover the original appearance of the settlement, including the terrain and building groups. Analysis is conducted after the creation of the restoration model.

Historical data used in the restoration process is categorized into maps and cadastral information. Maps include the 1895 Japanese Army survey maps (Scale: 1/50000), 1904 "Taiwan Fort Maps" (Scale: 1/20000), 1926 "Taiwan Topographic Maps", 1960," Taiwan Economic Planning Version Topographic Map "(Scale: 1/25000), and 1980 "Aerial Survey Map" (Scale: 1/5000). Cadastral data include the 1898--1945 "the land registration book" on changes in land ownership, land division, merger, and sale or lease of lands, as well as the 1913 cadastral blueprints used until 1991 (Scale: 1/1200), totaling 11, and cadastral maps from 1991, which have been digitalized but have not been re-surveyed (Scale: 1/3500).

In order to make up for the inadequacy of the abovementioned historical data, the study conducted a survey on the current conditions of Hua-Zhai settlement in 2012, primarily focusing on the use and division of the land, as well as the building groups and status of the surrounding topography. The study drew a restoration map based on the information gathered at the site. The restoration map is made into a 3D model, which then converted into an STL file and imported into the CFD software for further analysis. Due to the limitations in historical data and current information, the earliest recovery time for Hua-Zhai settlement is 1913. The procedure for settlement restoration and 3D model construction is as follows:

1. Topographic map restoration: The 1895 and 2008 topographic maps are overlaid on top of each other; this method is used for terrain restoration. First, the result of the overlay is partitioned and aligned for comparison and correction. A new recovery topographic map is then drawn based on these corrections, the contour lines of which are made into a 3D terrain model.

2. Cadastral map restoration: Cadrastal maps of the Hua-Zhai settlement were used from 1913 to about 1970. The government agency in charge of these maps have repeatedly recorded and revised the original version to reflect changes in land type as well as in the status of ownership. Consequently, the study has used the information on these maps including those on land mergers, land divisions, and changes in land 
ownership. The earliest restoration can be traced back to the 1913 cadastral and land entries of Hua-Zhai settlement.

Government agencies have made notes and revisions on the original image many times to show changes in the land, change in ownership, and other types of information. Consequently, the 1913 cadastral data and land headings are restored through land numbers showing land mergers and divisions, as well as information on the changes in land ownership.

3. Restoration of the building groups location delineation and roads: Using the "land accounts" as a basis, to find the building sites and land headings for the roads, which will serve as restoration bases for the location and number of buildings. Then, based on the information on the land headings and cadastral maps, find the roads and fields marked on the 1913 cadastral restoration map before nesting said map and the restored 3D terrain model.

4. Restoration of the building groups: First, conduct a survey on the age and measurements of the existing buildings and make a configuration diagram of the building groups constructed about 1913. Then, statistical data of the exterior architectural dimensions of the existing buildings is used to determine those of the buildings that do not exist anymore. Afterwards, based on the breadth and depth of the land on the restored cadastral map, build a 3D model in accordance with the positions shown on the post-restoration cadastral map.

\section{CFD simulation}

In this study the environment surrounding Hua-Zhai settlement and the building groups within the settlement in 1913 have been restored based on cadastral maps and topographic maps and converted into 3D models to be imported into CFD for simulating the wind environments of Hua-Zhai settlement during winter and summer. The geometry and the boundaries simulated by CFD are shown in Table 1. The scope of simulation is centered on the Hua-Si of Hua-Zhai settlement and extended outward by $400 \mathrm{~m}$. The overall simulative boundary condition is set to be $800 \mathrm{~m}(\mathrm{~N}-\mathrm{S}) \times 800 \mathrm{~m}(\mathrm{E}-\mathrm{W})$ $\times 250 \mathrm{~m}$ (altitude)(Fig. 4), and with Hua-Zhai settlement building group as the area of focus with the scope of $400(\mathrm{~N}-\mathrm{S}) \times 500 \mathrm{~m}(\mathrm{E}-\mathrm{W})$. The most proper mesh size is located in the focus region. Because the width of the roads in Hua-Zhai settlement is 2-3 meters, the $\mathrm{X}$ and $\mathrm{Y}$ axes of smallest grid in the focus area is $2 \mathrm{~m} \times 2 \mathrm{~m}$. Extended outward from the focus region, the mesh size gradually grows larger ( $\mathrm{X}$ axis grows to5 and $8 \mathrm{~m}$; $\mathrm{Y}$ axis grows to 8 and $24 \mathrm{~m}$ ). The mesh size of the vertical axis of the focus region is $0.5 \mathrm{~m}$, also growing larger as it extends from the focus region. The amount of the meshes of this simulation is 4,498,848 in total. Wind speed as a function of height above the ground was assumed to follow a power law distribution. The maximum terrain elevation within the simulation scope is $20.5 \mathrm{~m}$, such that the index value $(\alpha)$ is set to be 0.25 in accordance with the Modified Rules of Taiwan Building Wind Resistance Design Regulation and Specification (Construction and Planning Agency, 2014). It is generally applied to small towns or areas with many obstacles at the heights of residential house $(10$ to $20 \mathrm{~m})$ or higher, which is applicable to the conditions of lands within the simulation scope of Hua-Zhai settlement.

Next, to discuss winter and summer, the simulations of winter (November to March) and summer (June to September) are respectively conducted. The prevailing wind in winter is the NNE monsoon and the wind speed is $7.15 \mathrm{~m} / \mathrm{s}$. The prevailing wind in summer is the SSW monsoon and its wind speed is $3.64 \mathrm{~m} / \mathrm{s}$. 
Table1. CFD simulation settings

\begin{tabular}{cc}
\hline Inflow direction & NNE(Winter), SSW $($ Summer $)$ \\
\hline Velocity $(\mathbf{m} / \mathbf{s})$ & $7.15 \mathrm{~m} / \mathrm{s}($ Winter $), 3.64 \mathrm{~m} / \mathrm{s}($ Summer $)$ \\
\hline Boundary volume $(\mathbf{L} \times \mathbf{E} \times \mathbf{H})$ & $800 \mathrm{~m} \times 800 \mathrm{~m} \times 250 \mathrm{~m}$ \\
\hline Mesh number & $\fallingdotseq 4498848$ \\
\hline Reference height $(\boldsymbol{\delta})$ & $25.28 \mathrm{~m}$ \\
\hline Power law profile $(\boldsymbol{\alpha})$ & 0.25 \\
\hline Roughness height $(\mathbf{Z b})$ & $20 \mathrm{~m}$ \\
\hline
\end{tabular}

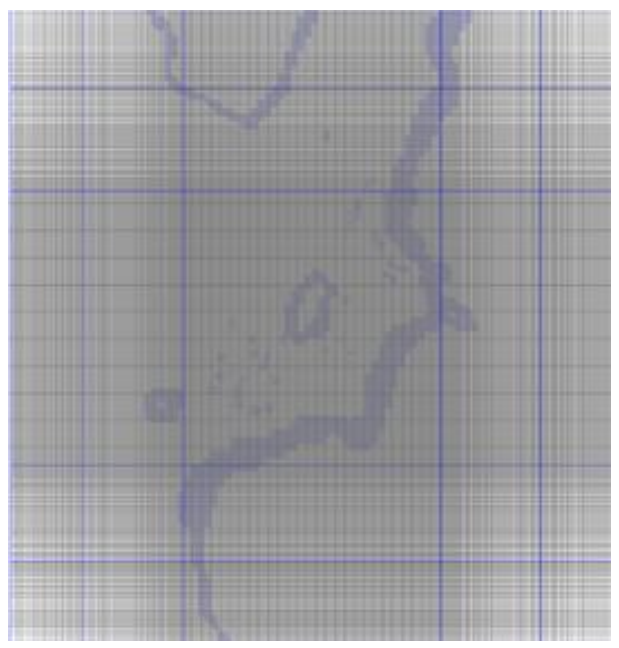

Figure 4. CFD simulation model grid

\section{Results and Discussion}

\section{Principles and impact of site selection}

The most basic principles for site selection found in the ancient books: "Tao TeChing," the "Sheng Ma Chapter" of "Guanzi," and the "Book of Odes". The principles include "Qi exists where the place is surrounded by hills and embraced by watercourses,""Ward off the yin while embracing the yang,"'backed by hills while facing watercourses," and "High in front and low at the back." Using these principles to analyze the terrain of Hua-Zhai settlement and its surroundings, it is known that the settlement faces the Taiwan Strait (facing watercourses), is surrounded by hills (with the back to the hills), as if the back of the settlement embraces a virtual space; this configuration adheres to the Feng Shui criterion of "surrounded by hills and embraced by watercourses." In fengshui, the mountains alludes to the "yin" and the body of water alludes to the "yang." The location of the Hua-Zhai settlement adheres to the principle of "warding off the yin while embracing the yang," which can also be described as "backed by hills facing the watercourses." From the ancient books, it can be comprehended that a location with these conditions can "hide the winds to keep the vital energy." These words refer to being able to surround the winds and keep the "qi." Because "qi" has been retained in the place, it becomes a location very suitable for living. Furthermore, the area located in the direction in which Hua-Zhai settlement faces the sea is low-lying. The terrain gradually becomes higher towards the back of the 
settlement, eventually forming hills. This adheres to the criterion "High in front and low at the back."

In addition, in terms of the principles for the wind, the ancient books describe that the place needs to have wind and that the wind speed can neither be too strong or too weak. Places where the wind blows gently are best suitable for living. Wangan Island is beset by strong monsoon winds during winter. The average wind speed is $7.15 \mathrm{~m} / \mathrm{s}$, with maximum average wind speed of $24.6 \mathrm{~m} / \mathrm{s}$, making it difficult for plants for grow. Moreover, the growth and height of plants are repressed because of this. However, plants and crops can be planted in the Hua-Zhai settlement and from the residents' oral history information, it is found that the strong winds could be heard but not felt as residents walked through streets and alleys of Hua-Zhai settlement during winter. In the hot summer afternoons, the wind blew through the settlement streets. From the status survey conducted by the study, it is found that, in the afternoon, residents often sit in shady areas between alleys to rest and enjoy the cool outdoor breeze. Thus the speculation those local residents looked for wind and its appropriate speed to ensure that they have a place suitable for long-term residence.

\section{Simulation Analysis}

Affected by surrounding topography, the buildings in Hua-Zhai settlement are distributed along the slow slope in two clusters. Most building groups and main streets are in the main cluster located at an altitude of around $2.3 \mathrm{~m}$, while other building groups and streets are scattered among altitudes of 4.7-6.3m. With "wind" being the major local weather feature, CFD wind environment simulation is implemented for analyzing the $1.5 \mathrm{~m}$ pedestrian wind field of Hua-Zhai settlement during winter and summer in order to understand the relationship between environment conditions and the site selection and planning of historical settlement.

In winter, the main wind direction in Hua-Zhai settlement is NNE, as confirmed by the simulation results (Figs. 5, 6, 7). The winds are blocked on the northeast side by Hutou Mountain (Fig. 1 Spot A) and Fengmen Mountain (Fig. 1 Spot C). As the winds near the settlement, they grow weaker due to the topography. At the place within the building group, where elevation is at 3.2 meters, as the winds approach the settlement square, the pedestrian wind speed at an altitude $1.5 \mathrm{~m}$ is reduced to $3.3-4.2 \mathrm{~m} / \mathrm{s}$, while that on the road is reduced to $0.6-1.2 \mathrm{~m} / \mathrm{s}$. For the other buildings, which are built along the terrain, distributed at an altitude of $4.7-6.3 \mathrm{~m}$, as well as roads distributed at an altitude of $4.7 \mathrm{~m}$, pedestrian wind speed goes down to $1.5-3 \mathrm{~m} / \mathrm{s}$. For roads distributed at an elevation of $6.3 \mathrm{~m}$, pedestrian wind field goes down to $1.8-3.9 \mathrm{~m} / \mathrm{s}$. From this information, it can be concluded that the settlement is able to avoid the strong winds during winter. The wind speed of the pedestrian wind field within the settlement is between $0.6-4.2 \mathrm{~m} / \mathrm{s}$. Without considering going out for a walk, temporary stay, or gender factor, the wind speed value of the settlement in winter is within the comfort range of Taiwan's pedestrian wind field.

In summer, the main wind direction is SSW. Because Hua-Zhai settlement faces the Taiwan Strait with its back surrounded by numerous small hills, the building groups are built along the terrain. The primary direction of the summer winds is SSW. The winds come from the side facing the sea due to the position of the settlement location. Moreover, because the street and major wind direction form a narrow angle of approximately 5 - 22.5 degrees, the side facing the wind is able to receive ventilation. From the simulation results (Figs. 8, 9, 10), it can be seen that majority of the building 
groups are located at an elevation of $2.3 \mathrm{~m}$; the wind speed of the pedestrian wind field of the streets and the settlement square ranges from $0.7-2.6 \mathrm{~m} / \mathrm{s}$. For other buildings distributed at an elevation of $4.7 \mathrm{~m}$, the wind speed of the pedestrian wind field on the street ranges from $1.5-3.3 \mathrm{~m} / \mathrm{s}$. During the summer, the speed of the summer winds ranges between $0.7-3.3 \mathrm{~m} / \mathrm{s}$. the smallest wind speed value is higher than $0.6 \mathrm{~m} / \mathrm{s}$, which exceeds the basic ventilation standards of the settlement environment. This improves the tolerance residents have for the outdoor temperature.

Due to the topographical environment and the spatial arrangement and planning of Hua-Zhai settlement, including the arrangement of the buildings and the location of the settlement, Hua-Zhai settlement can block winter monsoon winds effectively during winter and provide a good pedestrian wind field in the settlement. The opening between the hills surrounding the settlement and the sea front of it as well as the way the roads are laid out allow the southwest monsoon winds to blow into the settlement in the summer. Moreover, the angle produced by the streets and the wind direction not only allows ventilation, but it also increases wind speed.

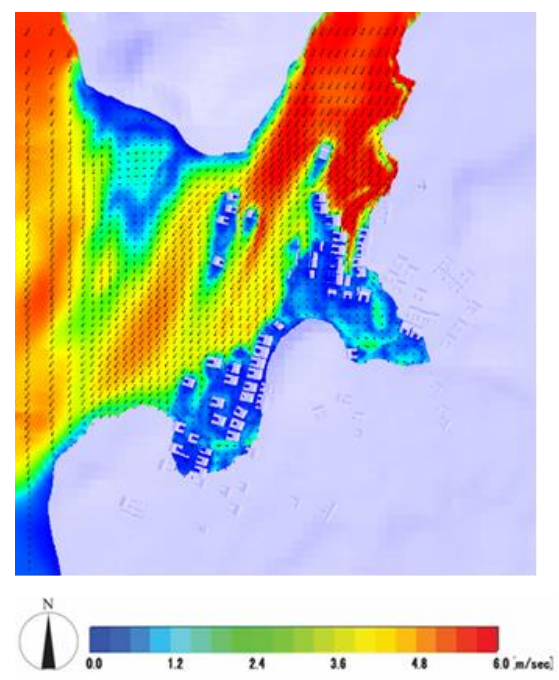

Figure 5. The simulation of $1.5 \mathrm{~m}$ wind field at an elevation of $2.3 \mathrm{~m}$ in winter

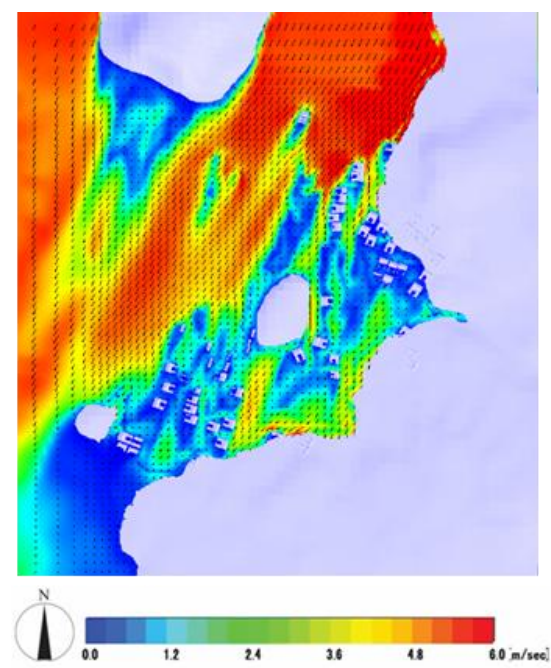

Figure 6. The simulation of $1.5 \mathrm{~m}$ wind field at an elevation of $4.7 \mathrm{~m}$ in winter 


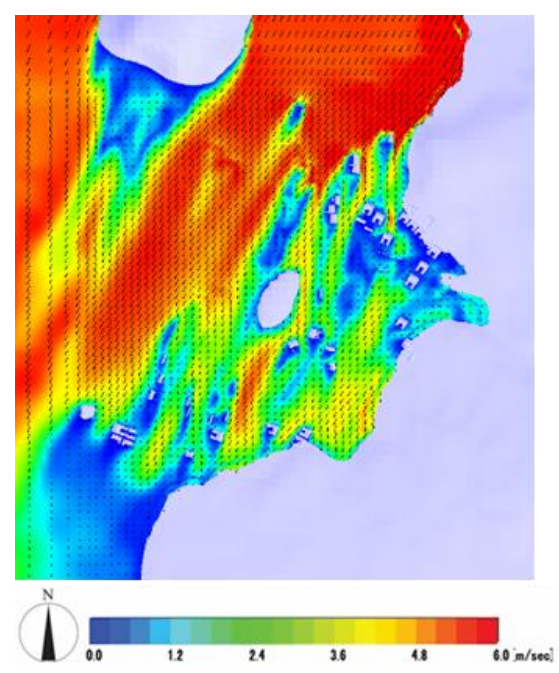

Figure 7. The simulation of $1.5 \mathrm{~m}$ wind field at an elevation of $6.3 \mathrm{~m}$ in winter

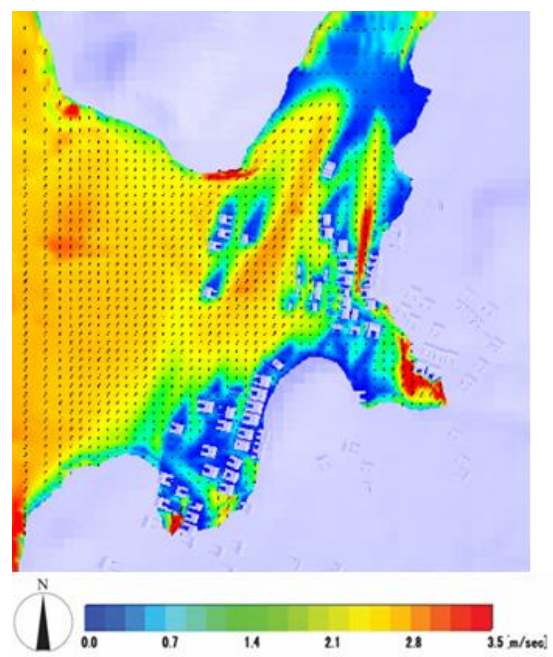

Figure 8. The simulation of $1.5 \mathrm{~m}$ wind field at an elevation of $2.3 \mathrm{~m}$ in summer

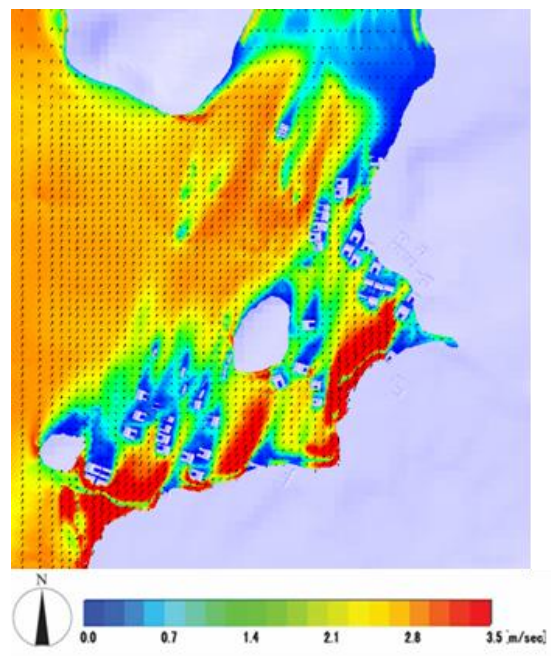

Figure 9. The simulation of $1.5 \mathrm{~m}$ wind field at an elevation of $4.7 \mathrm{~m}$ in summer

APPLIED ECOLOGY AND ENVIRONMENTAL RESEARCH 15(2):145-157. http://www.aloki.hu • ISSN 15891623 (Print) •ISSN1785 0037 (Online) DOI: http://dx.doi.org/10.15666/aeer/1502_145157 (c) 2017, ALÖKI Kft., Budapest, Hungary 


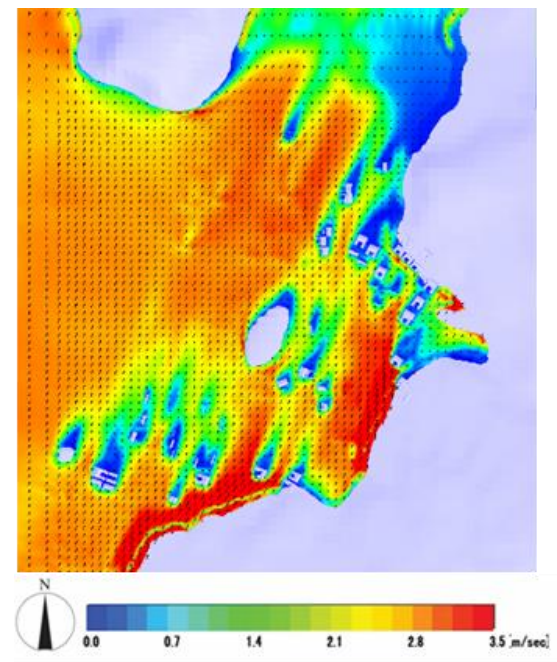

Figure 10. The simulation of $1.5 \mathrm{~m}$ wind field at an elevation of $6.3 \mathrm{~m}$ in summer

\section{Conclusion}

To create ideal living environments, people of ancient China use their life experiences to come up with knowledge in fengshui or geomancy, making it a basis for environmental norms and assessment system. Finding a suitable place of residence by applying the fengshui's site selection rules allows for sustainable living. Site selection methods include analysis of the terrain as well as analysis of the location and direction not only to ensure the quality of living and comfort of the residents but also to guarantee health and good fortune.

Initially, residents of Hua-Zhai settlement used their knowledge of fengshui to perform site selection, believing that this location was suitable for residence and eventually settling here. The study used the basic criteria for site selection to analyze Hua-Zhai settlement and its surrounding terrain. The site adheres to the fundamental site selection principles of fengshui including "Ward off the yin while embracing the yang,""Backed by hills while facing watercourses," and "High in front and low at the back." Because wind is the most significant factor affecting the quality of living of the residents, after comparing historical data, residents' narrations, and status survey data, it is ascertained that the site adheres to the site selection criteria for wind. Moreover the study uses 30 years of meteorological data and CFD software to simulate the wind environment of Hua-Zhai settlement. From the CFD simulation results, it is known that, affected by the terrain, the wind speed of winter monsoon winds is reduced before entering the settlement, allowing residents to grow crops and to enable residents to walk on a comfortable pedestrian wind field during winter. In addition, the building groups within the settlement are built along the gentle slope and are arranged in groups. This irregular configuration is conducive for the cluster buildings to avoid the wind. Furthermore, the settlement is surrounded by small hills, with the direction facing the sea the only opening. This allows the summer winds to blow along the terrain into the settlement from the sea. Because there is a narrow angle formed by the streets and the wind direction, this makes the winds stronger and allows the settlement to maintain ventilation. The wind speed values exceed the minimum ventilation standards for outdoor environment. From the abovementioned, it is known that Feng Shui is an accumulation of rules for living life. Based on the site selection principles, 
our ancestors have been able to find the Hua-Zhai settlement to live in an environment with harsh climatic conditions. Because in Hua-Zhai settlement, they are able to find shelter form the winds during winter and maintain ventilation during summer, the residents have a comfortable living environment, enabling them to settle and live here for many centuries.

\section{REFERENCES}

[1] Blocken, B., Janssen, W. D., van Hooff, T. (2012): CFD simulation for pedestrian wind comfort and wind safety in urban areas: General decision framework and case study for the Eindhoven University campus. - Environmental Modelling \& Software 30: 15-34.

[2] Blocken, B., Persoon, J. (2009): Pedestrian wind comfort around a large football stadium in an urban environment: CFD simulation, validation and application of the new Dutch wind nuisance standard. - Journal of Wind Engineering and Industrial Aerodynamics 97(5-6): 255-270.

[3] Cheng, H. H., Wang, F. (2005): Using a CFD approach for the study of street-level winds in a built-up area. - Building and Environment 40(5):617-631.

[4] Construction and Planning Agency, Ministry of the Interior (2014): Taiwan Building Wind Resistance Design Regulation and Specification, 2-11.

[5] D'Agostino, D., Congedo, P. M., Cataldo, R. (2013): Ventilation Control using Computational Fluid-dynamics (CFD) Modelling for Cultural Buildings Conservation. Procedia Chemistry 8: 83-91.

[6] Ding, Y. C., Chu, J. R.(1999): Evaluation criteria of pedestrian level wind around highrise buildings, research project report of Architecture and Building Research Institute, Ministry of the Interior, pp. 10-11.

[7] Guo, J-Y. (2011): Analysis of pedestrian level wind assessment criterion related factor, research project report of Architecture and Building Research Institute, Ministry of the Interior, pp. 27-70.

[8] He, X. X. (1995): The Source of Feng Shu. - Tapei: Yuan Bo Publishing Ltd. Press, pp. 87-89.

[9] Hsieh, C. M., Ni, M. C., Tan, H. (2014): Optimal wind environment design for pedestrians in transit-oriented-development planning - Journal of Environmental Protection and Ecology 3A: 1385-1392.

[10] Hsieh, C. M., Jan, F. C., Zhang, L. (2016): A simplified assessment of tree allocation on wind environment and shading affecting human comfort. - Urban Forest \& Urban Greening 18: 126-137.

[11] Hsieh, C. M., Huang H. C. (2016): Mitigating urban heat islands: A method to identify potential wind corridor for cooling and ventilation. - Computers, Environment and Urban Systems 57: 130-143.

[12] Li, Q., Sun, X., Chen, C., Yang, X. (2012): Characterizing the household energy consumption in heritage Nanjing Tulou buildings, China: A comparative field survey study. - Energy and Buildings 49: 317-326.

[13] Mak, M. Y., Ng, S. T. (2005): The art and science of Feng Shui-a study on architects' perception. - Building and Environment 40(3): 427-434.

[14] Mochida, A., Lun, I.Y.F. (2008): Prediction of wind environment and thermal comfort at pedestrian level in urban area. - Journal of Wind Engineering and Industrial Aerodynamics 96(10-11): 1498-1527.

[15] Nugroho, A. M., Ahmad, M. H.,Ossen, D. R. (2007): A Preliminary Study of Thermal Comfort in Malaysia's Single Storey Terraced Houses. - Journal of Asian Architecture and Building Engineering 6(1): 175-82. 
[16] Tang, L., Nikolopoulou, M., Zhao, F., Zhang, N. (2012): CFD modeling of the built environment in Chinese historic settlements. - Energy and Buildings 55: 601-606.

[17] Tang, L., Nikolopoulou, M., Zhang, N. (2014): Bioclimatic design of historic villages in central-western regions of China. - Energy and Buildings 70: 271-278.

[18] Yi, D., Yu, L., Hong, Y. (1996): Geomancy and the selection of architecture placement in ancient China. - Hebei: Hebei Science and Technology Press.

[19] Yuan, C., Ng, E. (2011): Building porosity for better urban ventilation in high-density cities: A computational parametric study. - Building and Environment 50: 176-189. 